\title{
Morfometria do timo de coelhos Nova Zelândia Branco tratados com gentamicina
}

\author{
Matheus Henrique Magalhães Silva ${ }^{1}$ \\ Maria Rita Pacheco ${ }^{1 *}$ \\ Annita Morais Girardi² \\ Marília Ferreira Rosa ${ }^{1}$ \\ Silvana Martinez Baraldi Artoni ${ }^{1}$ \\ Marcos Lania Araújo ${ }^{1}$ \\ ${ }^{1}$ Departamento de Morfologia e Fisiologia Animal \\ Faculdade de Ciências Agrárias e Veterinárias \\ Universidade Estadual Paulista "Júlio de Mesquita Filho" \\ Campus de Jaboticabal, Via de Acesso Prof. Paulo Donato Castellane s/nº, Zona Rural \\ CEP 14884-900, Jaboticabal - SP, Brasil \\ ${ }^{2}$ Departamento de Clínica e Cirurgia Veterinária, Faculdade de Ciências Agrárias e Veterinárias \\ Universidade Estadual Paulista "Júlio de Mesquita Filho" \\ Campus de Jaboticabal, Jaboticabal - SP, Brasil \\ *Autor para correspondência \\ rpacheco@fcav.unesp.br
}

Submetido em 31/03/2010

Aceito para publicação em 08/07/2010

\section{Resumo}

O objetivo deste estudo foi avaliar a morfometria da cortical e medular dos lóbulos tímicos individualizados de coelhos da raça Nova Zelândia Branco pela determinação da área $\left(\mu \mathrm{m}^{2}\right)$, perímetro $(\mu \mathrm{m})$, diâmetro máximo $(\mu \mathrm{m})$, diâmetro mínimo $(\mu \mathrm{m})$ e fator de forma. Deste modo, o timo de dez coelhos tratados com gentamicina e dez controles (machos e fêmeas) foram histologicamente processados. A dose de gentamicina utilizada e o tempo de administração deste aminoglicosídeo foram adequados e condizentes à recomendação terapêutica. Este antibiótico não alterou a morfometria deste órgão e não foi imunodepressor.

Unitermos: coelho, gentamicina, morfometria, timo

\section{Abstract}

Thymus morphometry of New Zealand White Rabbits treated with gentamicin. The aim of this study was to evaluate the morphometry of cortical and medullary thymic lobes individualized by determination of area $\left(\mu \mathrm{m}^{2}\right)$, perimeter $(\mu \mathrm{m})$, maximum and minimum diameter $(\mu \mathrm{m})$ and shape factor in New Zealand White rabbits. The spleens of ten rabbits treated with gentamicin and ten control rabbits (males and females) were histologically processed. The gentamicin dosage and the time of administration of this aminoglicoside were according to therapeutic recommendation. This antibiotic did not cause any alteration in the morphometry of the spleen, and it seemed not to be an immunosuppressive drug.

Key words: gentamicin, morphometry, rabbit, thymus 


\section{Introdução}

Histologicamente, o timo é coberto por uma cápsula de tecido conjuntivo denso que se projeta para dentro como septos, dividindo parcial e completamente o órgão em lóbulos. O parênquima de cada lóbulo está organizado em uma região cortical, formada por linfócitos T predominantemente pequenos e densamente acumulados, células reticulares epiteliais e macrófagos e em uma região medular constituída também por linfócitos, porém, em menor quantidade que a cortical e células reticulares epiteliais, em concentração maior do que a cortical, dispostas em arranjo concêntrico, formando os corpúsculos de Hassal, e macrófagos. Desta forma, a cortical e a medular possuem os mesmos tipos celulares, porém em proporções diferentes, ressaltando que as células mais abundantes são os linfócitos $\mathrm{T}$, em diversos estágios de maturação, e as células reticulares epiteliais.

As principais funções do timo incluem: o desenvolvimento de linfócitos $\mathrm{T}$ imunocompetentes a partir dos precursores derivados da medula óssea; a proliferação de clones de células $\mathrm{T}$ maduras nãoativadas para suprir os linfócitos circulantes e os tecidos periféricos; o desenvolvimento da autotolerância imunológica; a secreção de hormônios (timulina, timopoietina e a timosina $\alpha_{1}$ e $\beta_{4}$ ) e de outros fatores solúveis que regulam a maturação das células $\mathrm{T}$, a proliferação e a função dentro do timo e dos tecidos periféricos (Young e Heath, 2001).

Os linfócitos podem ser classificados em dois tipos principais, com diversos subtipos de acordo com o local onde se diferenciam e com os diferentes receptores presentes em suas membranas. Nos linfócitos B (linfócito B e linfócito B de memória), esses receptores são imunoglobulinas e nos linfócitos $\mathrm{T}$ (linfócito $\mathrm{T}$ citotóxico, linfócito $\mathrm{T}$ helper, linfócito $\mathrm{T}$ supressor e linfócito $\mathrm{T}$ de memória) são moléculas protéicas chamadas TCR (T-Cell Receptors). São caracterizados por apresentarem em suas membranas plasmáticas receptores de antígenos denominados de TCR, que permite o reconhecimento de uma ampla variedade de antígenos pelas células $\mathrm{T}$. Na superfície celular, esta molécula encontra-se associada a um complexo de peptídeos conhecidos coletivamente como CD3 (Roitt et al., 1999).

Os aminoglicosídeos formam um grupo de antibióticos que se assemelham entre si na sua atividade antimicrobiana, características farmacocinéticas e toxicidade (Spinosa et al., 2002; Rang et al., 2004). A gentamicina é um antibiótico de amplo espectro derivada de espécies do actinomiceto Micromonospora (Gilman, 1996). Estes antibióticos podem produzir graves efeitos tóxicos relacionados com a dose, que podem aumentar com a duração do tratamento. Os principais riscos consistem em ototoxicidade e nefrotoxicidade (Rang et al., 2004). Adams (2003) relatou que os aminoglicosídeos são tóxicos, pois causaram alterações sobre as membranas lisossômica, mitocondrial e plasmática das células dos túbulos contorcidos proximais do néfron. A literatura também informa que estas substâncias podem interagir diretamente com o sistema imunológico, atuando como imunodepressor. Entretanto, outros estudiosos sobre a influência dos antibióticos no sistema imune não evidenciaram efeitos imunodepressores para a gentamicina (Munster et al., 1977; Shcherbakova et al., 1977; Seklecki et al., 1978; Khan et al., 1979; Burgaleta et al., 1982; Kerk et al., 1983; El-Hawary et al., 1984; Venezio et al., 1985; Ibrahim et al., 1988; Artsimovich et al., 1991; Banerjee et al., 1991; Aprikian et al., 1992; Van Bambeke et al., 1993; Aoshiba et al., 1995; Sakaeva e Lazareva, 1998; Asha et al., 1999; Sacha et al., 1999).

Assim, este trabalho objetivou pesquisar a possibilidade de ocorrência de lesões no timo, pelo uso deste fármaco, em animais de laboratório, mediante a morfometria das regiões cortical e medular dos lóbulos tímicos, pois se acredita, com base na literatura clássica, que a gentamicina, pela sua ligação aos fosfolipídeos da membrana plasmática (Adams, 2003), possa alterá-la nos linfócitos $\mathrm{T}$, resultando em disfunções imunológicas. Desta forma, supõe-se que alterações morfométricas destas regiões tímicas poderão ocorrer em consequência das lesões morfológicas nos linfócitos $\mathrm{T}$, população celular abundante e em diversos estágios de maturação, neste órgão. 


\section{Material e Métodos}

Para este estudo utilizou-se vinte coelhos adultos, com peso médio de 2,5kg, hígidos, da raça Nova Zelândia Branco, divididos em quatro grupos de cinco animais, da seguinte forma: machos controle, fêmeas controle, machos tratados e fêmeas tratadas. Estes animais foram mantidos em gaiolas metálicas individuais, dotadas de comedouros fixos e bebedouros automáticos, com água e alimentação ad libitum (ração para manutenção), no biotério do Departamento de Morfologia e Fisiologia Animal da FCAV, Campus de Jaboticabal, UNESP.

Para esta pesquisa, os animais foram tratados por sete dias com 4,4mg/kg de gentamicina $\left(\right.$ Gentocin $\left.^{\circledR}\right)$ subcutânea. No oitavo dia, os animais foram eutanasiados e o baço de cinco machos e de cinco fêmeas tratados e de cinco machos e de cinco fêmeas controle, após coletado, foi fixado em solução de Bouin, por $24 \mathrm{~h}$, e processado, rotineiramente, para a inclusão em parafina. Após a microtomia semiseriada, à espessura de $5 \mu \mathrm{m}$, com intervalos de $1000 \mu \mathrm{m}$, os cortes histológicos foram corados pelas técnicas do Tricrômico de Masson (Tolosa et al., 2003) e observados à microscopia de luz para a análise morfométrica. Este estudo foi realizado medindo-se 30 corpúsculos esplênicos e os seus centros germinativos da polpa branca de cada animal, pela determinação em micrômetros $(\mu \mathrm{m})$ de parâmetros tais como: área $\left(\mu \mathrm{m}^{2}\right)$, perímetro $(\mu \mathrm{m})$, diâmetro máximo $(\mu \mathrm{m})$, diâmetro mínimo $(\mu \mathrm{m})$ e fator de forma. Estas medidas foram efetuadas mediante o sistema analisador de imagens, Image Pro-plus, acoplado a um microscópio binocular, ambos da Olympus.

O fator de forma, cuja fórmula é expressa matematicamente por $\frac{(\text { perímetro })^{2}}{(4 . \pi \text {.área })}$, está programado, como os demais parâmetros, na memória do programa Image Pro-plus. O menor valor deste fator é igual a um, significando que a forma do citoplasma e/ou do núcleo se assemelha à forma de um círculo. Este fator é calculado, indiretamente, a partir da área do círculo, que tem por equação п. $\mathrm{R}^{2}$, como também a partir do perímetro do círculo, com a equação 2.п.R. Pela substituição da área e do perímetro obtêm-se:

Fator de forma:

$$
\frac{(2 \cdot \pi \cdot R)^{2}}{4 \cdot \pi \cdot\left(\pi \cdot R^{2}\right)}=\frac{\left(4 \cdot \pi^{2} \cdot R^{2}\right)}{\left(4 \cdot \pi \cdot \pi \cdot R^{2}\right)}=\frac{\left(4 \cdot \pi^{2} \cdot R^{2}\right)}{\left(4 \cdot \pi^{2} \cdot R^{2}\right)}=1
$$

Quando este fator for maior que a unidade, entendese que a forma do citoplasma e/ou do núcleo não é circular.

O experimento foi realizado conforme um esquema fatorial 2 X 2 (tratados e não tratados) X sexos, com cinco repetições de acordo com o delineamento inteiramente casualizado.

As médias foram comparadas mediante o teste de Tukey a $5 \%$ de probabilidade segundo Pimentel Gomes (2000).

\section{Resultados}

Os resultados morfométricos das medidas efetuadas nas regiões cortical e medular dos lóbulos tímicos estão apresentados nas Tabelas $1 \mathrm{e} 2$. A maneira como se procedeu à morfometria destas regiões está ilustrada na Figura 1.

A análise da Tabela 1 indica que: não houve diferença significativa $(\mathrm{p}>0,05)$, entre os animais dos grupos controle e tratado com gentamicina assim como entre tratamento e sexo dos animais; houve diferença significativa $(p<0,05)$, entre machos e fêmeas, apenas para o diâmetro mínimo, com o maior valor médio para as fêmeas. A Tabela 2 indica que não houve diferença significativa $(p>0,05)$ entre os animais do grupo controle $e$ do grupo tratado com gentamicina, entre machos e fêmeas assim como entre o tratamento e o sexo dos animais.

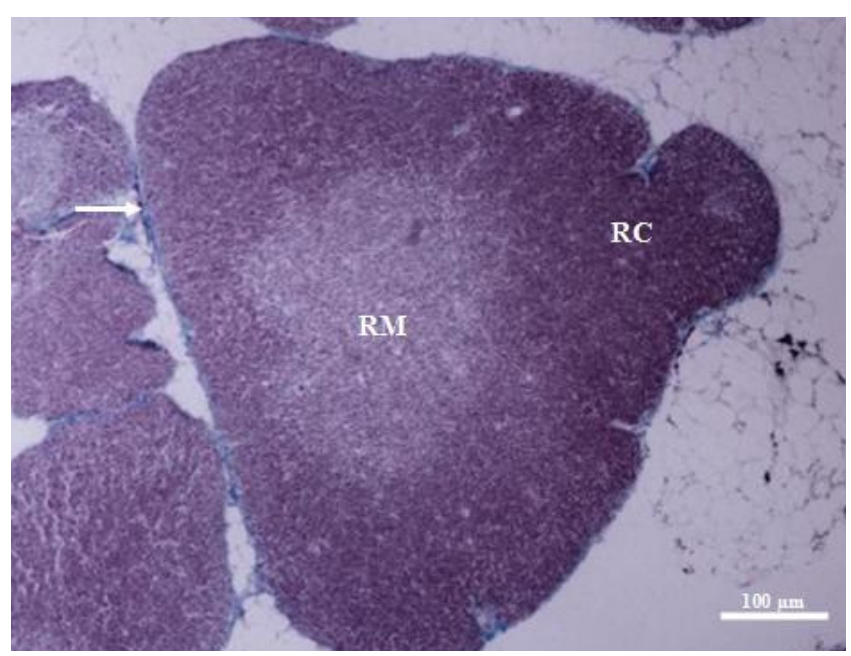

FIGURA 1: Fotomicrografia do timo de coelho da raça Nova Zelândia Branco, indicando: lóbulos individualizados por septo de tecido conjuntivo denso (seta branca) região cortical (RC) e região medular (RM). Tricrômico de Masson. 
TABELA 1: Valores de F, coeficiente de variação (CV), médias e desvio padrão (DP) obtidos nas análises de variância para os parâmetros mensurados na região cortical dos lóbulos tímicos individualizados do timo de coelhos da raça Nova Zelândia Branco, tratados com gentamicina e do grupo controle.

\begin{tabular}{|c|c|c|c|c|c|c|}
\hline Tratamento $(\mathrm{T})$ & & Área $\left(\mu m^{2}\right)$ & $\begin{array}{c}\text { Diâmetro máximo } \\
(\mu \mathrm{m})\end{array}$ & $\begin{array}{c}\text { Diâmetro mínimo } \\
(\mu \mathrm{m})\end{array}$ & $\begin{array}{c}\text { Perímetro } \\
(\mu \mathrm{m})\end{array}$ & Fator de forma \\
\hline \multirow{2}{*}{ Controle } & Média & $843686,62 \mathrm{a}$ & $1494,29 \mathrm{a}$ & $846,86 \mathrm{a}$ & $4033,66 \mathrm{a}$ & $1,27 \mathrm{a}$ \\
\hline & DP & 184094,21 & 186,29 & 104,72 & 505,69 & 0,05 \\
\hline \multirow{2}{*}{ Tratado } & Média & $783609,27 \mathrm{a}$ & $1382,32 \mathrm{a}$ & $813,91 \mathrm{a}$ & $3791,36 \mathrm{a}$ & $1,28 \mathrm{a}$ \\
\hline & DP & 248632,80 & 208,88 & 131,27 & 578,02 & 0,05 \\
\hline Teste F & & $0,43 \mathrm{~ns}$ & $1,63 \mathrm{~ns}$ & $0,50 \mathrm{~ns}$ & $1,04 \mathrm{~ns}$ & $0,10 \mathrm{~ns}$ \\
\hline \multicolumn{7}{|l|}{$\operatorname{Sexo}(S)$} \\
\hline $\mathrm{F}$ & $\begin{array}{l}\text { Média } \\
\text { DP }\end{array}$ & $\begin{array}{c}903091,56 \mathrm{a} \\
175632,66\end{array}$ & $\begin{array}{c}1494,15 \mathrm{a} \\
174,56\end{array}$ & $\begin{array}{c}888,34 \mathrm{a} \\
90,46\end{array}$ & $\begin{array}{c}4103,10 \mathrm{a} \\
459,40\end{array}$ & $\begin{array}{c}1,28 \mathrm{a} \\
0,06\end{array}$ \\
\hline M & $\begin{array}{l}\text { Média } \\
\text { DP }\end{array}$ & $\begin{array}{c}724204,33 \mathrm{a} \\
221560,69\end{array}$ & $\begin{array}{c}1382,46 \mathrm{a} \\
218,86\end{array}$ & $\begin{array}{c}772,43 \mathrm{~b} \\
114,68\end{array}$ & $\begin{array}{c}3721,93 \mathrm{a} \\
575,05\end{array}$ & $\begin{array}{c}1,28 \mathrm{a} \\
0,04\end{array}$ \\
\hline Teste F & & $3,84 \mathrm{~ns}$ & $1,62 \mathrm{~ns}$ & $6,12 *$ & $2,57 \mathrm{~ns}$ & $0,06 \mathrm{~ns}$ \\
\hline \multicolumn{7}{|l|}{ Interação TxS } \\
\hline Teste F & & $0,83 \mathrm{~ns}$ & $0,73 \mathrm{~ns}$ & $1,01 \mathrm{~ns}$ & $0,23 \mathrm{~ns}$ & $1,25 \mathrm{~ns}$ \\
\hline $\mathrm{CV}$ & & 25,09 & 13,63 & 12,61 & 13,58 & 4,10 \\
\hline
\end{tabular}

ns: não significativo a $5 \%$ de probabilidade. ${ }^{*}$ :significativo a $5 \%$ de probabilidade. Médias seguidas pelas mesmas letras minúsculas nas colunas não diferem significantemente entre si pelo Teste de Tukey a $5 \%$ de probabilidade.

TABELA 2: Valores de F, coeficiente de variação (CV), médias e desvio padrão (DP) obtidos nas análises de variância para os parâmetros mensurados na região medular dos lóbulos tímicos individualizados do timo de coelhos da raça Nova Zelândia Branco, tratados com gentamicina e do grupo controle.

\begin{tabular}{|c|c|c|c|c|c|c|}
\hline Tratamento $(\mathrm{T})$ & & Área $\left(\mu \mathrm{m}^{2}\right)$ & $\begin{array}{c}\text { Diâmetro máximo } \\
(\mu \mathrm{m})\end{array}$ & $\begin{array}{c}\text { Diâmetro mínimo } \\
(\mu \mathrm{m})\end{array}$ & $\begin{array}{c}\text { Perímetro } \\
(\mu \mathrm{m})\end{array}$ & Fator de forma \\
\hline \multirow{2}{*}{ Controle } & Média & $235866,47 \mathrm{a}$ & $706,59 \mathrm{a}$ & $378,16 \mathrm{a}$ & $1878,75 \mathrm{a}$ & $1,27 \mathrm{a}$ \\
\hline & DP & 74224,29 & 135,80 & 47,99 & 342,86 & 0,11 \\
\hline \multirow{2}{*}{ Tratado } & Média & $200283,25 \mathrm{a}$ & $623,01 \mathrm{a}$ & $373,15 \mathrm{a}$ & $1686,68 \mathrm{a}$ & $1,20 \mathrm{a}$ \\
\hline & DP & 70943,87 & 124,11 & 61,12 & 330,21 & 0,09 \\
\hline Teste F & & $1,09 \mathrm{~ns}$ & $1,86 \mathrm{~ns}$ & $0,04 \mathrm{~ns}$ & $1,45 \mathrm{~ns}$ & $2,08 \mathrm{~ns}$ \\
\hline \multicolumn{7}{|l|}{$\operatorname{Sexo}(S)$} \\
\hline $\mathrm{F}$ & $\begin{array}{l}\text { Média } \\
\text { DP }\end{array}$ & $\begin{array}{c}227795,14 \mathrm{a} \\
72208,09\end{array}$ & $\begin{array}{c}678,84 \mathrm{a} \\
134,78\end{array}$ & $\begin{array}{c}383,32 \mathrm{a} \\
37,21\end{array}$ & $\begin{array}{c}1801,98 \mathrm{a} \\
352,31\end{array}$ & $\begin{array}{c}1,24 \mathrm{a} \\
0,11\end{array}$ \\
\hline M & $\begin{array}{l}\text { Média } \\
\text { DP }\end{array}$ & $\begin{array}{c}208354,57 \mathrm{a} \\
76300,26\end{array}$ & $\begin{array}{c}650,76 \mathrm{a} \\
138,29\end{array}$ & $\begin{array}{c}367,99 \mathrm{a} \\
67,36\end{array}$ & $\begin{array}{c}1763,49 \mathrm{a} \\
349,49\end{array}$ & $\begin{array}{c}1,24 \mathrm{a} \\
0,11\end{array}$ \\
\hline Teste F & & $0,33 \mathrm{~ns}$ & $0,21 \mathrm{~ns}$ & $0,38 \mathrm{~ns}$ & $0,06 \mathrm{~ns}$ & $0,01 \mathrm{~ns}$ \\
\hline \multicolumn{7}{|l|}{ Interação TxS } \\
\hline Teste F & & $0,01 \mathrm{~ns}$ & $0,00 \mathrm{~ns}$ & $1,19 \mathrm{~ns}$ & $0,00 \mathrm{~ns}$ & $0,12 \mathrm{~ns}$ \\
\hline $\mathrm{CV}$ & & 34,95 & 20,62 & 14,80 & 19,99 & 8,69 \\
\hline
\end{tabular}

ns: não significativo a $5 \%$ de probabilidade. *:significativo a $5 \%$ de probabilidade. Médias seguidas pelas mesmas letras minúsculas nas colunas não diferem significantemente entre si pelo Teste de Tukey a $5 \%$ de probabilidade

\section{Discussão}

Estas evidências sobre os resultados indicaram que este aminoglicosídeo, administrado em coelhos da raça Nova Zelândia Branco, na dose terapêutica e no período recomendado, não alterou o sistema imunológico destes animais, considerando-se os aspectos morfométricos pesquisados nas regiões cortical, formada por linfócitos $\mathrm{T}$ predominantemente pequenos e densamente acumulados, células reticulares epiteliais e macrófagos e na medular, 
constituída também por linfócitos, porém, em menor quantidade que a cortical e células reticulares epiteliais, em concentração maior do que a cortical, dispostas em arranjo concêntrico, formando os corpúsculos de Hassal, e macrófagos. Estes achados se respaldam em outras pesquisas, também realizadas com o mesmo antibiótico, por alguns pesquisadores, tais como: Munster et al. (1977) comprovaram que a gentamicina estimulou levemente a síntese de DNA em culturas de linfócitos; Shcherbakova et al. (1977) evidenciaram que este aminoglicosídeo administrado em doses múltiplas de 1 e $10 \mathrm{mg} / \mathrm{kg}$, durante seis a 14 dias, não alterou a atividade fagocítica do sistema reticuloendotelial, macrófagos, da cavidade abdominal de camundongos. Porém, em doses de 20 e $40 \mathrm{mg} / \mathrm{kg}$, houve alguma inibição da fagocitose pelos macrófagos dessa cavidade; Ibrahim et al. (1988) verificaram, in vitro, que a gentamicina não alterou as respostas mitogênicas em linfócitos $\mathrm{B}$ e $\mathrm{T}$ do baço de camundongos e nos linfócitos do sangue periférico humano. In vivo, este aminoglicosídeo também não afetou a transformação de células esplênicas de camundongos em resposta ao mitógeno; Artsimovich et al. (1991) constataram que a gentamicina suprimiu a resposta imune somente em camundongos não imunodeprimidos. Baseados nisto, concluíram que pode ser usada no tratamento de doenças, mesmo em presença de imunodeficiência; Aprikian et al. (1992) observaram, em camundongos, que este aminoglicosídeo, em doses bactericidas, suprimiu a atividade dos macrófagos ou não os alterou. Todavia, em doses sub-bactericidas, aumentou a atividade fagocítica destas células; Van Bambeke et al. (1993) evidenciaram que a gentamicina a influenciou pouco ou não influenciou a permeabilidade da membrana de lipossomos e de células cultivadas; Sakaeva e Lazareva (1998) verificaram que este aminoglicosídeo não alterou a atividade fagocítica de macrófagos e neutrófilos em camundongos normais; Asha et al. (1999), ao estudarem os efeitos da gentamicina no baço e linfonodos de coelhos, não encontraram nenhum sinal de lesão celular ou citotoxicidade, nos cortes histológicos destes órgãos; Sacha et al. (1999) notaram que a gentamicina, em baixas concentrações $(0,4$ a $5,0 \mathrm{mg} / \mathrm{L})$, não influenciou a fagocitose nem a destruição intracelular do material fagocitado por macrófagos peritoniais de coelho e, em altas concentrações (40mg/L ou mais), inibiu significativamente a ativação dos macrófagos.
Os relatos dos autores mencionados, ao estudarem parcialmente o sistema imune, com referência a não alteração em macrófagos e linfócitos $\mathrm{B}$ e $\mathrm{T}$ confirmam as observações adquiridas, neste estudo, com alusão às regiões cortical e medular, as quais se apresentaram histologicamente normais, estruturas compostas por linfócitos T, macrófagos e células reticulares epiteliais. Pelo exposto, pode-se aventar a hipótese de que estas regiões não foram influenciadas pela dose de gentamicina administrada, o que pareceu manter o potencial imune do timo, considerando-se que os macrófagos presentes tanto na cortical como na medular não foram alterados e, por desempenharem, mediante a produção de IL-1 e IL-6, funções imunes importantes tais como a ativação de granulócitos, sensibilização de linfócitos $\mathrm{T}$ a sinais moleculares, diferenciação dos linfócitos $\mathrm{B}$ e crescimento dos timócitos. Pode-se, ainda, sugerir que a proliferação e a diferenciação dos linfócitos $T$ não tenham sofrido alteração, lembrando que as células reticulares epiteliais produzem timulina, timopoietina, timosina $\alpha_{1}$ e $\beta_{4}$, e fator tímico humoral, os quais atuando localmente, por secreção parácrina, estimulam a proliferação e a diferenciação dos linfócitos T. Vale ainda supor que a população de linfócitos $\mathrm{T}$ também não tenha sido influenciada pelo aminoglicosídeo, ora aqui estudado, salientando que estas células, por meio da produção de IL-2, IL-3, IL-4, IL-5, IL-6, IL-9 e IL10 , estimulam a proliferação de linfócitos $\mathrm{T}, \mathrm{B}, \mathrm{NK}$, de células hemocitopoéticas jovens, eosinófilos, timócitos e mastócitos, controlam o isotipo do linfócito $\mathrm{B}$, mudando para IgG e IgE, produção de IgA e diferenciação dos linfócitos B. Além disso, estas sugestões se apóiam nos achados de Asha et al. (1999), que ao estudarem os efeitos da gentamicina no baço e linfonodos de coelhos, também não encontraram nenhum sinal de lesão celular ou citotoxicidade, nos cortes histológicos destes órgãos linfóides dos animais utilizados, lembrando que a zona paracortical do linfonodo, à semelhança do timo, contém linfócitos T. Os resultados obtidos neste estudo, ainda, refletiram as sugestões de Exon et al. (1989) quanto ao uso de dose adequada e tempo de administração não excessivo ao recomendado.

Pelos resultados obtidos, pode-se concluir que a dose de gentamicina utilizada e o tempo de administração deste aminoglicosídeo foram adequados e condizentes à 
recomendação terapêutica. Este antibiótico não alterou a morfometria deste órgão e não foi imunodepressor.

\section{Referências}

Adams, H. R. 2003. Farmacologia e Terapêutica em Veterinária. $8^{\mathrm{a}}$ ed. Guanabara Koogan, Rio de Janeiro, Brasil, 1034pp.

Aoshiba, K.; Nagai, A.; Konno, K. 1995. Erythromycin shortens neutrophil survival by accelerating apoptosis. Antimicrobial Agents Chemotherapy, 39 (4): 872-877.

Aprikian, V. S.; Mikhailova, A. A.; Petrov, R. V. 1992. Changes in the phagocytic activity of macrophages under the action of different doses of antibiotics. Zhurnal Mikrobiologii Epidemiologii i Immunobiologii, (9-10): 71-74.

Artsimovich, N. G.; Nastoiashchaia, N. N.; Mul'tanovskaia, V. N.; Matvienko, M. A.; Navashin, P. S. 1991. Study of the immunotropic activity of aminoglycoside antibiotics. Antibiotiki Khimioterapiya, 36 (2): 27-29.

Asha, H. B.; Honnegowda; Vijayasarathi, S. K.; Rao, S.; Krishnappa, G.; Narayana, K.; Jayakumar, K. 1999. Effect of gentamicin on spleen and lymphnodes of rabbits. Indian Journal of Animal Sciences, 69: 795-796.

Bacha Jr., W. J.; Bacha, L. M. 2003. Atlas Colorido de Histologia Veterinária. $2^{\mathrm{a}}$ ed. Roca, São Paulo, Brasil, 457pp.

Banerjee, M.; Kamdar, S.; Kshirsagar, N. A. 1991. Effect of antibiotics on polymorphonuclear function in iron deficiency anaemia patients \& normal volunteers. Indian Journal of Medical Research, 94: 102-106.

Burgaleta C.; Martínez-Beltrán, J.; Bouza, E. 1982. Comparative effects on moxalactam and gentamicin on human polymorphonuclear leukocyte functions. Antimicrobial Agents Chemotherapy, 21 (5): 718-720.

El-Hawary, A.; Hemida, K.; Sabbour, M. 1984. In vitro effect of some antibiotics on phagocytic index of human neutrophils. Chemioterapia, 3 (6): 354-357.

Exon, J. H.; Stevens, M. G.; Koller, L. D.; Mather, G. G. 1989. Immunotoxicity assessment of gentamycin and liquamycin. Veterinary and Human Toxicology, 31 (5): 427-430.

Gartner, L. P.; Hiatt, J. L. 1999. Tratado de Histologia em Cores. Guanabara Koogan, Rio de Janeiro, Brasil, 426pp.

Gilman, A. G. 1996. As Bases Farmacológicas da Terapêutica. $9^{a}$ ed. McGraw Hill, Rio de Janeiro, Brasil, 1436pp.

Haschek, W. M.; Rousseaux, C. G. 1998. Fundamentals of Toxicologic Pathology. Academic Press, San Diego, USA, 563pp. Ibrahim, M. S.; Maged, Z. A.; Haron, A.; Khalil, R. Y.; Attallah, A. M. 1988. Antibiotics and immunity: effects of antibiotics on mitogen responsiveness of lymphocytes and interleukin-2 production. Chemioterapia, 7 (6): 369-372.
Junqueira, L. C; Carneiro, J. 2008. Histologia Básica. 11 ${ }^{\mathrm{a}}$ ed. Guanabara Koogan, Rio de Janeiro, Brasil, 524pp.

Kerk, D. K.; Myers, C. P.; Hays, E. F. 1983. Gentamicin reduces the self-renewal capacity of murine pluripotent hemopoietic stem cells. Experimental Hematology, 11 (9): 819-827.

Khan, A. J.; Evans, H. E.; Glass, L.; Khan, P.; Chang, C. T.; Nair, S. R. 1979. Abnormal neutrophil chemotaxis and random migration induced by aminoglycoside antibiotics. Journal of Laboratory and Clinical Medicine, 93 (2): 295-300.

Munster, A. M.; Loadholdt, C. B.; Leary, A. G.; Barnes, M. A. 1977. The effect of antibiotics on cell-mediated immunity. Surgery, 81 (6): 692-695.

Pimentel Gomes, F. 2000. Curso de Estatística Experimental. 14a ed. Pimentel Gomes, Piracicaba, Brasil, 477pp.

Rang, H. P.; Dale, M. M.; Ritter, J. M.; Moore, P. K. 2004. Farmacologia. $5^{\text {a }}$ ed. Elsevier, Rio de Janeiro, Brasil, 904pp.

Roitt, I.; Brostoff, J.; Male, D. 1999. Imunologia. $5^{\text {a }}$ ed. Manole, São Paulo, Brasil, 423pp.

Ross, M. H.; Romrell, L. J.; Kaye, G. I. 1995. Histology: a Text and Atlas. $3^{\mathrm{a}}$ ed. Williams \& Wilkins, Baltimore, USA, 823pp.

Sacha, P. T.; Zaremba, M. L.; Jakoniuk, P. 1999. The influence of antibiotics on phagocytic and bacteriocidal activity of rabbit peritoneal macrophages stimulated by filtrates of cultured t-lymphocytes. Medycyna Doswiadczalna i Mikrobiologia, 51 (3-4): 399-412.

Sakaeva, D. D.; Lazareva, D. N. 1998. The effect of gentamycin on immunity in immunodeficiency and the action of immunomodulators. Eksperimental'naia i klinicheskaia farmakologiia, 61 (3): 50-53. Seklecki, M. M.; Quintiliani, R.; Maderazo, E. G. 1978. Aminoglycoside antibiotics moderately impair granulocyte function. Antimicrobial Agents Chemotherapy, 13 (3): 552-554.

Shcherbakova, E. G.; Rastunova, G. A.; Medvedeva, M. M; Zhuravleva, T. P.; Kuchushev, Sha. 1977. Effect of gentamicina on the state of cellular resistance. Antibiotiki, 22 (5): 413-417.

Spinosa, H. S.; Górniak, S. L.; Bernardi, M. M. 2002. Farmacologia Aplicada à Medicina Veterinária. $3^{\mathrm{a}}$ ed. Guanabara Koogan, Rio de Janeiro, Brasil, 752pp.

Tolosa, E. M. C.; Rodrigues, C. J.; Behmer, O. A.; Freitas Neto, A. G. 2003. Manual de Técnicas para Histologia Normal e Patológica. $2^{\mathrm{a}}$ ed. Manole, São Paulo, Brasil, 331pp.

Van Bambeke, F.; Minueto-Leclercq, M. P.; Schanck, A.; Brasseur, R.; Tulkens, P. M. 1993. Alterations in membrane permeability induced by aminoglycoside antibiotics: studies on liposomes and cultured cells. European Journal of Pharmacology, 247 (2): 155-168.

Venezio, F. R.; Divincenzo, C. A. 1985. Effects of aminoglycoside antibiotics on polymorphonuclear leukocyte function in vivo. Antimicrobial Agents Chemotherapy, 27 (5): 712-714.

Young, B.; Heath, J. W. 2001. Wheater: histologia funcional, texto e atlas em cores. $4^{a}$ ed. Guanabara Koogan, Rio de Janeiro, Brasil, 415pp. 